\title{
Ontogeny of the (pro)renin receptor
}

\author{
Renfang Song ${ }^{1}$, Graeme Preston ${ }^{1}$ and Ihor V. Yosypiv ${ }^{1}$
}

BACKGROUND: This study examined temporal expression of the (pro)renin receptor ((P)RR), during renal, heart, lung, and brain organogenesis in the mouse.

METHODS: (P)RR expression was determined by quantitative reverse-transcription $P C R$, western blotting, and immunohistochemistry.

RESULTS: Brain, kidney, and lung (P)RR mRNA levels increased progressively during gestation and peak on postnatal day (P)10. (P)RR protein contents were high during gestation in all organs studied and declined with maturation. Brain (P)RR was expressed most prominently in the ependymal lining of the ventricles. In the embryonic day (E)16.5 and E18.5 metanephros, (P)RR was present in the ureteric bud and ureteric bud-derived collecting ducts. In the fetal heart, (P)RR was expressed diffusely in the myocardium, whereas pulmonary $(P)$ RR was detected at highest levels in the epithelium of branching airways. Treatment of newborn kidneys with the angiotensin (Ang) II type 1 receptor (AT,R) antagonist candesartan increased (P)RR mRNA levels.

CONCLUSION: (P)RR gene and protein expressions in the brain, kidney, heart, and lung are developmentally regulated in a tissue-specific manner. Endogenous Ang II, acting via the $A T, R$, exerts a negative feedback on (P)RR in the newborn kidney. These findings suggest that high (P)RR protein levels observed during gestation may play a role in brain, kidney, heart, and lung organogenesis.

$\mathbf{T}$ he renin-angiotensin (Ang) system plays a central role in the regulation of arterial blood pressure, fluid/electrolyte homeostasis, and kidney development. In the renin-Ang system, renin cleaves angiotensinogen to generate Ang I (1). Ang I is converted by angiotensin-converting enzyme to Ang II, which acts via the Ang II type 1 receptor $\left(\mathrm{AT}_{1} \mathrm{R}\right)$ and Ang II type 2 receptor $\left(\mathrm{AT}_{2} \mathrm{R}\right)(1)$. Renin is synthesized in juxtaglomerular cells of the afferent arterioles of the kidney as (pro) renin and is then converted to active renin by cleavage of a 43-amino-acid N-terminal prosegment by proteases (2-4). Binding of (pro)renin to the (pro)renin receptor ((P)RR) results in increased processing of angiotensinogen to generate Ang II and to activate intracellular signaling pathways that are independent of the angiotensinogen/Ang II axis $(5,6)$.

The $(\mathrm{P}) \mathrm{RR}$ protein is a single transmembrane domain receptor encoded by the ATP6AP2 (ATPase-associated protein
2)/(P)RR gene (subsequently referred to as $(P) R R$ ) located on the $\mathrm{X}$ chromosome in humans (5). The (P)RR protein exists in three forms: (i) a full-length $35-39 \mathrm{kDa}$ form composed of 3 domains: an extracellular domain, a single transmembrane domain, and a cytoplasmic domain; (ii) a $28 \mathrm{kDa}$ soluble form found in plasma and urine; and (iii) a truncated form containing transmembrane and cytoplasmic domains (4).

During adult life, $(\mathrm{P}) \mathrm{RR}$ is abundantly expressed in the kidney, heart, and brain (7-9). Although our understanding of the precise role of the $(\mathrm{P}) \mathrm{RR}$ in development and disease is rudimentary, emerging evidence indicates that $(\mathrm{P}) \mathrm{RR}$ plays an important role in cardiovascular, renal, and brain development and function. Cardiomyocyte-specific ablation of the $(P) R R$ in mice results in early mortality due to heart failure (10). Targeted genetic inactivation of the $(P) R R$ in the podocyte in mice causes podocyte foot process retraction, nephrotic syndrome, and death from renal failure during early postnatal life $(11,12)$. Studies in zebrafish demonstrate that $(\mathrm{P}) \mathrm{RR}$ mutations result in brain malformations and early embryonic lethality (13). Moreover, hypomorphic mutations in the $(P) R R$ are causally linked to the development of $\mathrm{X}$-linked mental retardation in humans (14). Given that the precise function of the (P)RR during kidney, lung, heart, and brain development is still emerging, we examined the spatiotemporal ontogeny of the $(\mathrm{P}) \mathrm{RR}$ in the kidney, lung, heart, and brain in the mouse.

\section{RESULTS}

\section{Developmental Changes in (P)RR Gene Expression}

The quantitative levels of (P)RR mRNA, as determined by real-time reverse-transcription PCR (RT-PCR), are shown in Figure 1a-d. In each tissue, the relative levels of (P)RR mRNA on embryonic day (E) 12.5 were assigned a value of 1 . During early embryonic development (E12.5-E14.5), (P)RR mRNA expression was low in all the tissues studied except in the heart and increased significantly thereafter. However, the temporal changes in (P)RR mRNA abundance differed with each organ. In the kidney, brain, and lung, (P)RR mRNA levels increased progressively with maturation. By contrast, cardiac (P)RR mRNA levels were high throughout gestation and the perinatal period, declined on postnatal day $(\mathrm{P}) 10$, and remained low in adult life. Whereas in the adult brain and lung (P)RR mRNA levels did not differ from levels observed on P10, (P)RR mRNA content was lower in adult as compared with P10 kidney. 
a

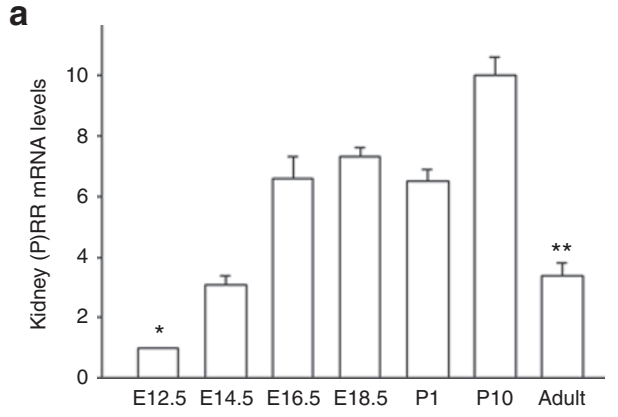

c

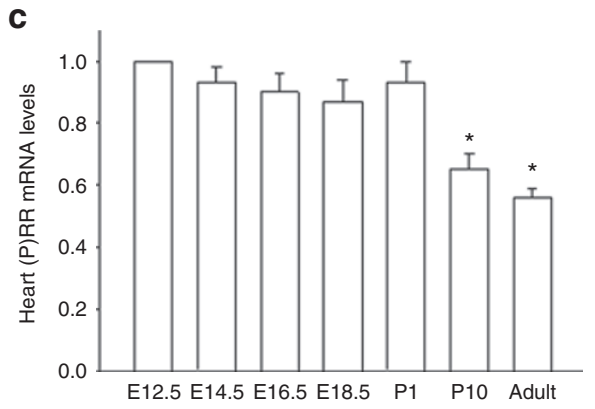

b
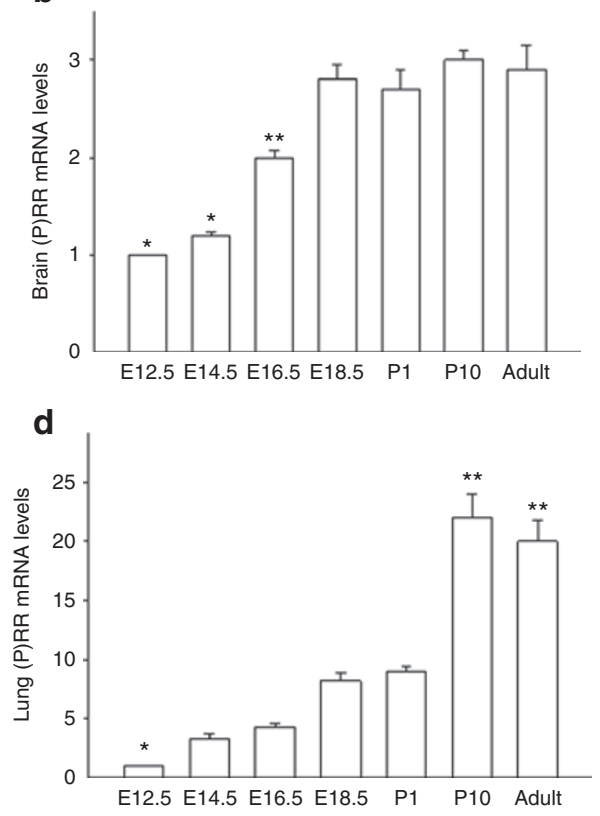

Figure 1. Bar graphs showing developmental expression of (P)RR mRNA factored per expression of GAPDH mRNA in the mouse (a) kidney, (b) brain, (c) heart, and (d) lung by quantitative reverse-transcription PCR. In a: ${ }^{*} P<0.05$ vs. E14.5-adult, ${ }^{* *} P<0.05$ vs. E16.5-P10; in b: ${ }^{*} P<0.05$ vs. E16.5adult, ${ }^{*} P<0.05$ vs. E18.5-adult; in c: ${ }^{*} P<0.05$ vs. E12.5-P1; in d: ${ }^{*} P<0.05$ vs. E18.5-adult, ${ }^{*} P<0.05$ vs. E12.5-P1. E, day of embryonic life; GAPDH, glyceraldehyde 3-phosphate dehydrogenase; $P$, day of postnatal life; $(P) R R$, (pro)renin receptor.

\section{Developmental Changes in (P)RR Protein Levels}

Western blot analysis revealed the presence of a single (P)RR band with the molecular weight of $37 \mathrm{kDa}$ in the developing kidney and heart (Figure 2). Additional less abundant $42 \mathrm{kDa}$ product was detected during early gestation in the developing brain and lung. (P)RR protein that migrates at $45 \mathrm{kDa}$ on western blot was reported previously in human mesangial cells, where it mediates the activation of Erk1/2 on binding of renin to (P)RR (5). Although the roles of 37 and $42 \mathrm{kDa}$ (P)RR isoforms in the embryonic brain and lung remain to be determined, the presence of two isoforms possibly reflects differences in $(\mathrm{P}) \mathrm{RR}$ glycosylation. (P)RR protein present was detected in all developing organs studied as early as on E12.5. In the developing heart, (P)RR mRNA was expressed at relatively high levels throughout gestation and declined on P10 and in adulthood (Figure 1c). Cardiac (P)RR protein levels were low on E12.5-E14.5, increased on E16.5, declined during later gestation and on P1, and decreased further on P10 and in adulthood (Figure $2 \mathrm{~d}$ ). In contrast to the temporal profile of $(\mathrm{P}) \mathrm{RR}$ mRNA levels, $(\mathrm{P}) \mathrm{RR}$ protein contents were high throughout gestation and declined gradually during postnatal development in the kidney, brain, and lung (Figures 1a,b,d and 2).

\section{Immunohistochemistry for (P)RR}

On E14.5, (P)RR was weakly expressed in a diffuse stippled manner throughout the brain (Figure 3). On E16.5 and E18.5, (P)RR was expressed most prominently in the ependymal lining of the ventricle and the mesenchyme. On E14.5, the (P)RR protein was expressed in the developing metanephros in the tubules and ureteric bud branches (Figure 4). On E16.5,
(P)RR was most prominent in the tubules that morphologically resemble collecting ducts. On E18.5, (P)RR was present in the tubules followed by glomerular mesangium. In the fetal heart, (P)RR was expressed diffusely in the myocardium (Figure 5). In the lung, $(\mathrm{P}) \mathrm{RR}$ was expressed at highest levels in the epithelium of the bronchial tree and in mesenchymal cells adjacent to airway epithelium (Figure 5).

\section{Effect of Animal Sex on (P)RR Gene Expression}

Whereas $(\mathrm{P}) \mathrm{RR}$ protein levels were lower in female brain and lung, they were higher in the female kidney and did not differ in the heart (Figure 6). (P)RR/ $\beta$-actin protein ratios (female:male) were as follows: brain: $0.21 \pm 0.03$ vs. $0.32 \pm 0.03$, $P<0.01$; lung: $0.17 \pm 0.01$ vs. $0.24 \pm 0.02, P<0.01$; kidney: $0.26 \pm 0.02$ vs. $0.20 \pm 0.02, P<0.01$. (P)RR/glyceraldehyde 3 -phosphate dehydrogenase protein ratios (female:male) in the heart did not differ $(0.19 \pm 0.03$ vs. $0.21 \pm 0.02, P=0.26)$ ( $n=3$ animals per group) (Figure 6). These findings demonstrate that $(\mathrm{P}) \mathrm{RR}$ expression in the brain, kidney, and lung during postnatal development is regulated in a sex-specific manner.

\section{Regulation of (P)RR by Ang II in the Newborn Kidney}

Treatment with candesartan ( $n=3$ kidneys) increased (P)RR mRNA levels as compared with treatment with media (control, $n=3$ kidneys $)(1.5 \pm 0.1$ vs. $1.0 \pm 0, P<0.01)$. By contrast, treatment with the $\mathrm{AT}_{2} \mathrm{R}$ antagonist $\mathrm{PD} 123319$ ( $n=3$ kidneys) did not alter $(\mathrm{P}) \mathrm{RR}$ mRNA levels as compared with those of controls $(0.93 \pm 0.1$ vs. $1.0 \pm 0, P=0.57)$. Therefore, endogenous Ang II exerts a tonic negative feedback on renal $(\mathrm{P}) \mathrm{RR}$ in the P1 kidney via the $\mathrm{AT}_{1} \mathrm{R}$. 
a

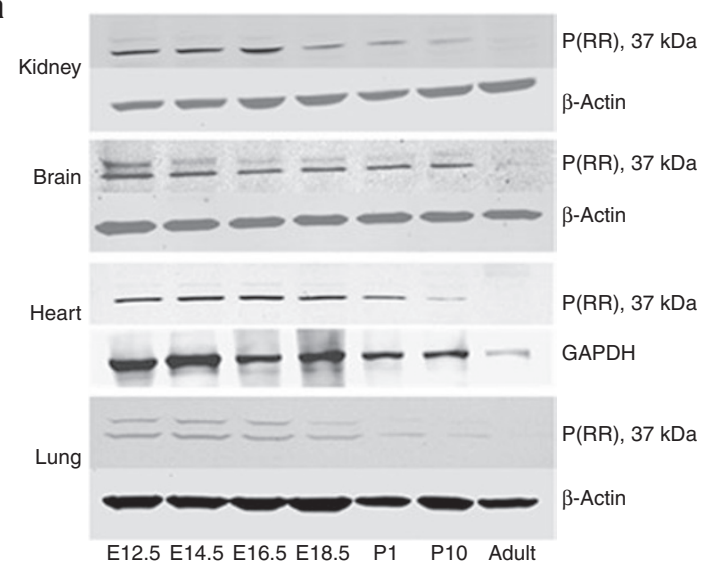

C

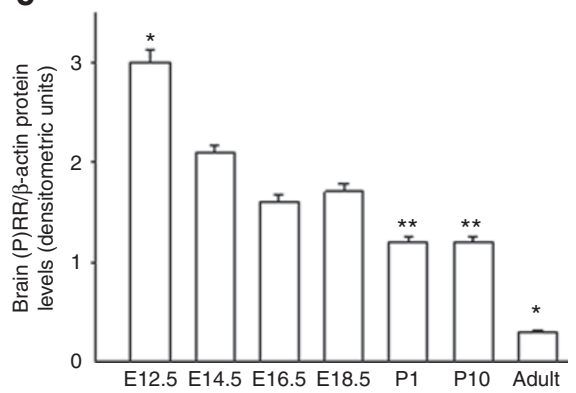

d

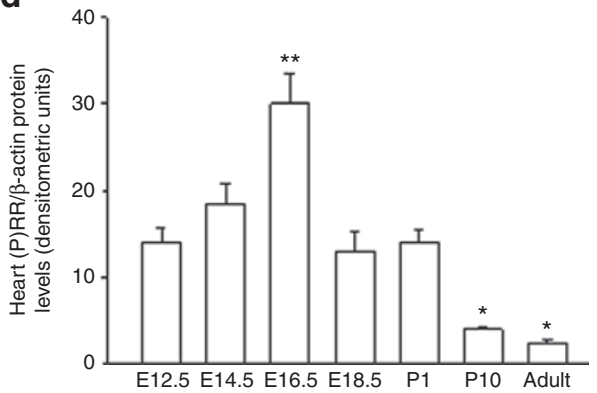

b
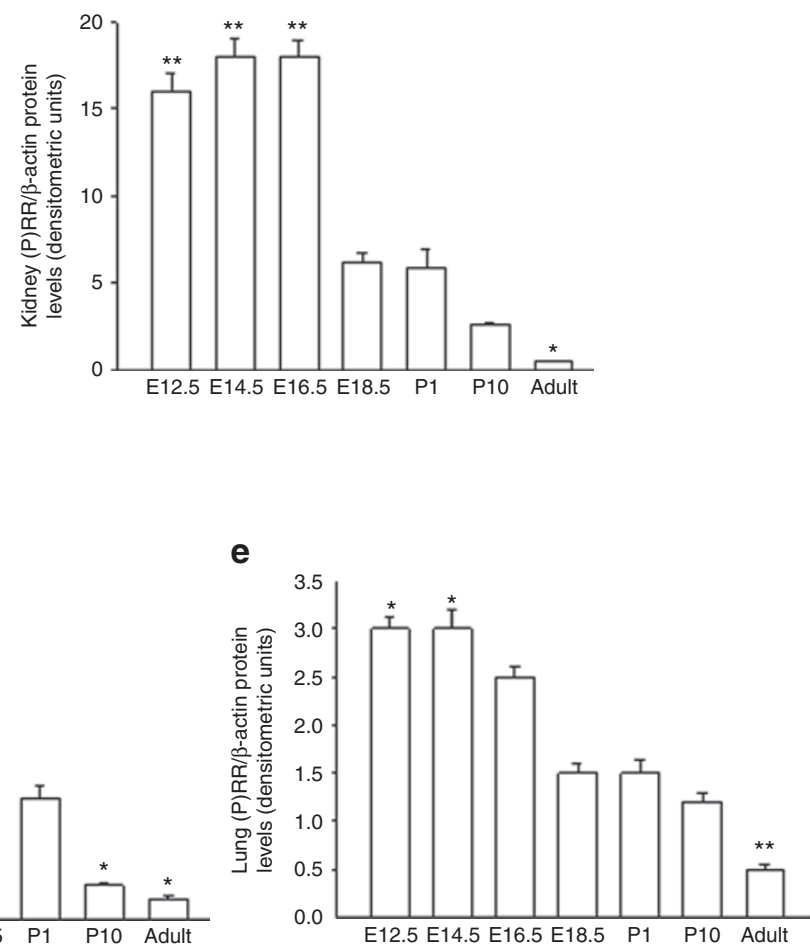

Figure 2. Developmental expression of (P)RR protein in the kidney, lung, brain, and heart. (a) Western blots (40 $\mu$ g total protein/lane) showing (P)RR and $\beta$-actin protein expression. (b-e) Bar graphs show the ontogeny of tissue-specific (P)RR protein expression factored per $\beta$-actin or GAPDH (heart) protein expression. (b) Kidney, ${ }^{*} P<0.05$ vs. all other groups; ${ }^{* *} P<0.05$ vs. E18.5-adult. (c) Brain, ${ }^{*} P<0.05$ vs. all other groups; ${ }^{* *} P<0.05$ vs. E12.5-E18.5 and adult. (d) Heart, ${ }^{*} P<0.05$ vs. all other groups; ${ }^{*} P<0.05$ vs. E12.5-E14.5 and E18.5-adult. (e) Lung, ${ }^{*} P<0.05$ vs. other groups; ${ }^{* *} P<0.05$ vs. other groups. E, day of embryonic life; GAPDH, glyceraldehyde 3-phosphate dehydrogenase; $\mathrm{P}$, day of postnatal life; (P)RR, (pro)renin receptor.

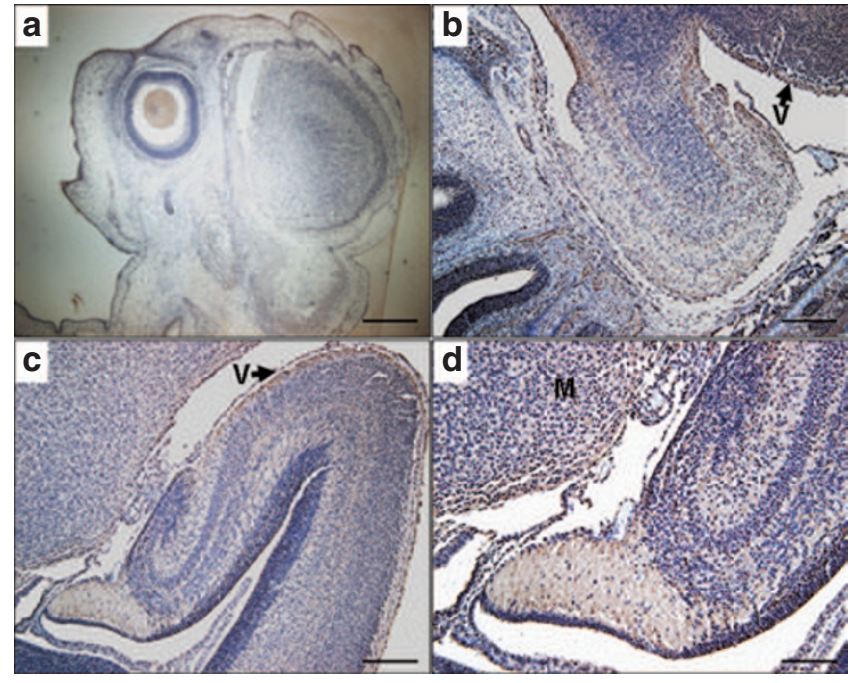

Figure 3. Immunolocalization of (P)RR protein in the fetal mouse brain on embryonic day (E)14.5, E16.5, and E18.5. (a) On E14.5, (P)RR immunoreactivity (brown staining) is present in a diffuse stippled manner throughout the brain (original magnification $\times 4$ ). (b) On E16.5, (P)RR is expressed most prominently in the ependymal lining of the ventricle $(\mathrm{V})$ (original magnification $\times 10)$. (c, d) On E18.5, (P)RR is present in the ependymal lining of the ventricle and the mesenchyme (M) (in c: original magnification $\times 10$; in d: original magnification $\times 20$ ). Bar $=100 \mu \mathrm{m}$. (P)RR, (pro)renin receptor.

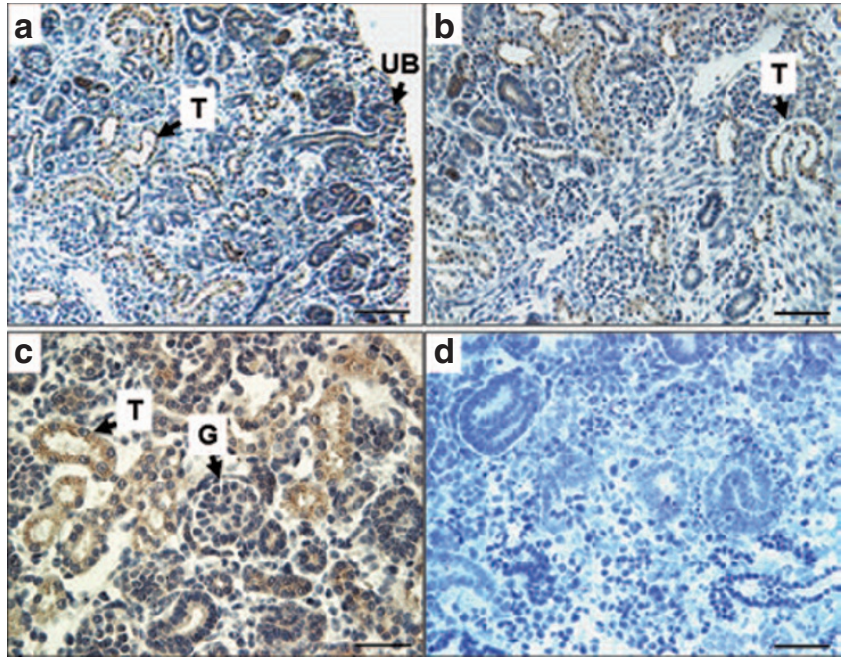

Figure 4. Immunolocalization of (P)RR protein in the fetal mouse kidney on embryonic day (E)14.5, E16.5 and, E18.5. (a) On E14.5, (P)RR is expressed in the tubules ( $T$ ) and the ureteric bud (UB) branches (original magnification $\times 20)$. (b) On E16.5, (P)RR is most prominent in the tubules that morphologically resemble collecting ducts (original magnification $\times 20)$. (c) On E18.5, (P)RR is most prominent in the tubules followed by glomeruli (G) (original magnification $\times 20$ ). (d) Control E18.5 section, where the addition of the primary antibody was omitted, demonstrates no staining (original magnification $\times 20$ ). Bar $=100 \mu \mathrm{m}$. (P)RR, (pro)renin receptor. 


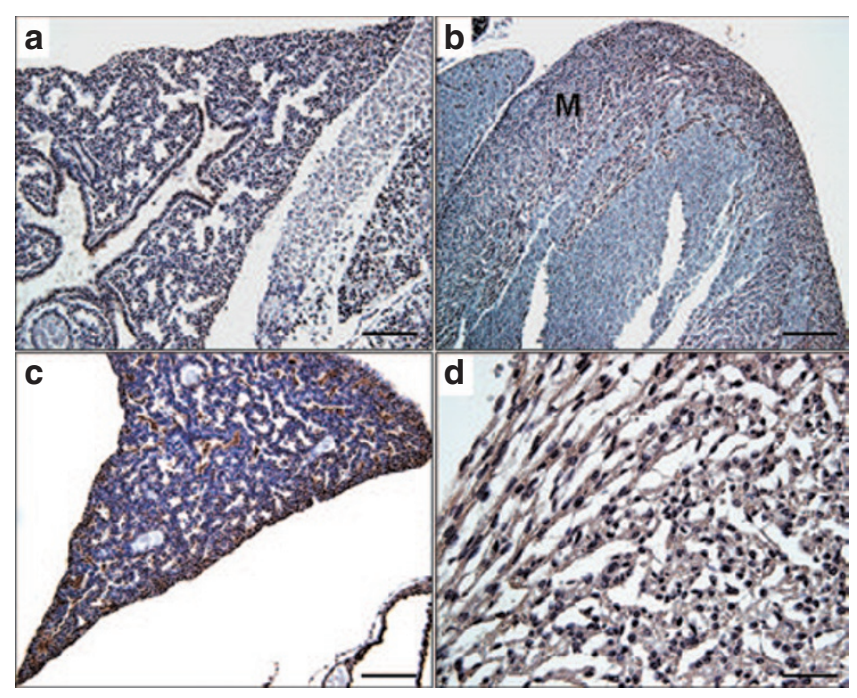

Figure 5. Immunolocalization of $(P) R R$ protein in the fetal mouse heart and lung on $(\mathbf{a}, \mathbf{b})$ E16.5 and (c,d) E18.5. (a,c) In the lung, (P)RR is expressed at highest levels in the epithelium of the bronchial tree $(\mathrm{Br})$ and in mesenchymal cells adjacent to airway epithelium (in a: original magnification $\times 20$, in c: original magnification $\times 10)$. $(\mathbf{b}, \mathbf{d})$ In the heart, $(P) R R$ immunoreactivity is present diffusely in the myocardium (M) (in b: original magnification $\times 20$, in $\mathbf{d}$ : original magnification $\times 60$ ). Bar $=100 \mu \mathrm{m}$. $E$, embryonic day; $(P) R R$, (pro)renin receptor.

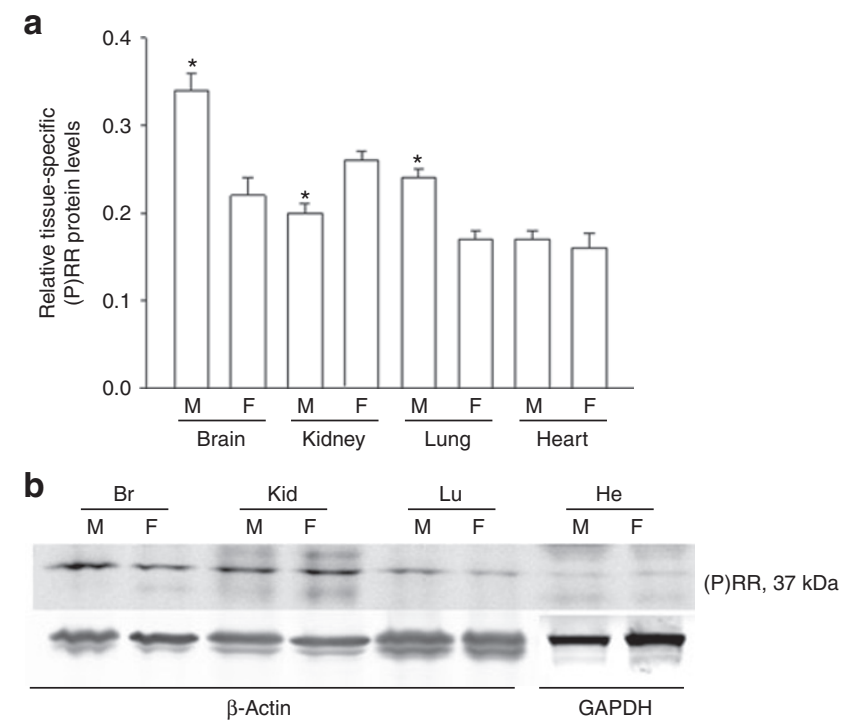

Figure 6. Effect of animal sex on (P)RR protein expression on postnatal day (P)10. (a) Bar graph shows tissue-specific (P)RR protein levels normalized to $\beta$-actin or GAPDH (heart). ${ }^{*} P<0.01$. (b) Western blots ( $40 \mu \mathrm{g}$ total protein/lane) showing (P)RR, $\beta$-actin, and GAPDH protein expression. $\mathrm{Br}$, brain; F, female; GAPDH, glyceraldehyde 3-phosphate dehydrogenase; He, heart; Kid, kidney; Lu, lung; $M$, male; (P)RR, (pro)renin receptor.

\section{DISCUSSION}

The current study demonstrates that $(\mathrm{P}) \mathrm{RR}$ is expressed in the developing kidney, lung, heart, and brain during embryonic development in the mouse. Moreover, (P)RR mRNA and protein are developmentally regulated in a tissue- and sex-specific manner.

We have chosen a mouse model to test the hypothesis that (P)RR gene expression is developmentally regulated in a tissue-specific manner because (P)RR-floxed mice have been generated and represent a valuable tool to further study the role of (P)RR during development (10-12). In the fetal mouse kidney, renin mRNA is first detected on E14.5 by in situ hybridization in a few scattered foci of cells (15). By E15.5, renin, a major ligand for $(\mathrm{P}) \mathrm{RR}$, is widely expressed in branches of the renal, interlobar, and arcuate arteries. With fetal maturation, renin expression shifts to its mature localization in juxtaglomerular cells (15-17). Renin synthesis and renin mRNA and Ang II levels are 20-fold and sixfold higher, respectively, in newborn than in adult kidneys (16-19). Global genetic inactivation of renin in mice causes arterial wall thickening, hypoplastic papilla, hydronephrosis, interstitial fibrosis, and glomerulosclerosis (20). Functionally, renin-null animals are polyuric and have a reduced ability to concentrate urine. One role for relatively high (P)RR protein levels observed in the developing kidney may be to bind and increase catalytic activity of (pro)renin to generate Ang I from angiotensinogen, resulting in the production of physiologically relevant concentrations of Ang II required for proper metanephric development (21). Another function of $(\mathrm{P}) \mathrm{RR}$ may be to modulate metanephric morphogenesis via renin/Ang II-independent activation of (P)RR downstream signaling pathways such as phosphatidylinositol 3-kinase/Akt or mitogen-activated protein kinases such as Erk1/2, canonical and noncanonical Wnt signaling, or interactions with vacuolar $\mathrm{H}^{+}$-ATPase (22-26). An important role for Erk1/2 and phosphatidylinositol 3-kinase/Akt in kidney development is demonstrated by the finding that inhibition of Erk1/2 or phosphatidylinositol 3-kinase/Akt decreases ureteric bud branching $(27,28)$. Given that $(\mathrm{P}) \mathrm{RR}$ is expressed at the apical surface of type A renal intercalated cells, where it colocalizes with the vacuolar $\mathrm{H}^{+}$-ATPase (8), (P)RR-vacuolar $\mathrm{H}^{+}$-ATPase cross talk may be important in differentiation of collecting duct cells involved in acid-base homeostasis.

A critical role for cardiac $(\mathrm{P}) \mathrm{RR}$ is evident from the observation that cardiomyocyte-specific ablation of the $(P) R R$ in mice results in early mortality due to heart failure (10). Transgenic overexpression of the $(P) R R$ in rats causes elevated blood pressure (29). Of note, polymorphism in the $(P) R R$ gene is associated with a high blood pressure in men (IVS5 $+169 \mathrm{C}>\mathrm{T}$ ) and left-ventricular hypertrophy in women $(+1513 \mathrm{~A}>\mathrm{G})(30,31)$. High (P)RR mRNA and protein levels observed in the fetal heart suggest a role for $(\mathrm{P}) \mathrm{RR}$ in heart development.

$(\mathrm{P}) \mathrm{RR}$ is expressed in the adult brain, where it plays a role in the neural control of cardiovascular functions, regulation of Erk1/2 signaling, and neuron differentiation $(5,32)$. The possibility that (P)RR may be important for brain development is supported by the findings that Xenopus embryos injected with (P)RR antisense morpholino oligonucleotides have small head size (25). Moreover, hypomorphic mutation in the $(P) R R$ is causally linked to the absence of Erk1/2 phosphorylation and the development of X-linked mental retardation in humans (14). Although the role of the (P)RR in the developing or adult lung remains to be determined, relatively high expression levels of the pulmonary $(\mathrm{P}) \mathrm{RR}$ protein throughout ontogeny support a novel role for $(\mathrm{P}) \mathrm{RR}$ in lung morphogenesis. 
We observed an apparent divergence between (P)RR mRNA and protein levels in several organs. Whereas (P)RR mRNA levels are relatively low during early gestation in the kidney, brain, and lung, (P)RR proteins are easily detected. By contrast, (P)RR mRNA/protein ratios increase in these organs during later gestation and postnatal development. Relatively low (P)RR mRNA/protein ratios observed during early gestation may be due to increased stability of nonabundant $(\mathrm{P})$ RR mRNA or to resistance of (P)RR protein to degradation. An additional mechanism that may account for the apparently divergent expression levels of (P)RR mRNA and protein may involve microRNAs that act to inhibit translation without targeting the message for degradation. In this regard, the expression of a gap junction channel, connexin 43 , is subject to developmental regulation by microRNAs during skeletal muscle development in the mouse (33). Further studies are necessary to delineate the molecular and cellular signals mediating the developmental changes in the $(\mathrm{P}) \mathrm{RR}$ expression.

The current study also demonstrates sex-associated difference in the expression of $(\mathrm{P}) \mathrm{RR}$ in the developing kidney, brain, and lung, suggesting that it may function differently in a male than in a female. These findings are consistent with the observation that $(\mathrm{P}) \mathrm{RR}$ mRNA abundance is greater in decidual explants collected from women carrying a female fetus (34).

In summary, the current study demonstrates that $(\mathrm{P}) \mathrm{RR}$ is expressed in the developing kidney, heart, lung, and brain as early as on E12.5 in the mouse. Moreover, (P)RR mRNA and protein expression are developmentally regulated in a tissue-specific manner. (P)RR expression in the developing kidney, brain, and lung is regulated in a sex-specific manner. Endogenous Ang II, acting via the $\mathrm{AT}_{1} \mathrm{R}$, exerts a negative feedback on (P)RR gene expression in the newborn kidney. We postulate that relatively high $(\mathrm{P}) \mathrm{RR}$ protein levels observed during gestation may play a role in kidney, lung, brain, and heart organogenesis.

\section{METHODS}

\section{Animals}

Tissues were dissected from CD1 mice (Charles River Laboratories, Wilmington, MA) on E12.5-E18.5 and on P1, P10, and P60 (adult male). All experiments involving mice were approved by the Tulane Institutional Animal Care and Use Committee.

\section{Quantitative Real-Time RT-PCR}

Quantitative real-time RT-PCR was used to determine the expression of (P)RR mRNA in the whole metanephroi, heart, lung, and brain. SYBR Green quantitative real-time RT-PCR with (P)RR-specific primers (SABiosciences, Frederick, MD) was conducted as described previously (35). The quantity of (P)RR mRNA expression was normalized to that of glyceraldehyde 3-phosphate dehydrogenase mRNA expression. For E12.5-E18.5, organs were pooled from one litter. For P1-P60, animals were segregated according to their age group, and the groups included four animals each. Three RNA samples from three separate organ pools for each gestational age studied and four RNA samples per each postnatal age group studied were analyzed in triplicate in each run. PCR reaction was performed three times.

\section{Western Blot Analysis}

Organs were homogenized in cold lysis buffer containing a cocktail of enzyme inhibitors (35). The samples were centrifuged, and the supernatants containing proteins ( $40 \mu \mathrm{g} / \mathrm{lane}$ ) were resolved on $10 \%$ sodium dodecyl sulfate-polyacrylamide gels and transferred to nitrocellulose membranes. The membranes were incubated with the specific goat primary polyclonal (P)RR (1:200, AB5959; Abcam, Cambridge, MA), $\beta$-actin (1:5,000; Sigma, St Louis, MO) or glyceraldehyde 3-phosphate dehydrogenase (1:5,000; Santa Cruz Biotechnology, Santa Cruz, CA) antibodies. Because $\beta$-actin cannot be used as a loading control for protein expression in the heart muscle (36), western blots for (P)RR expression in the heart tissue were reprobed with glyceraldehyde 3-phosphate dehydrogenase antibody. Immunoreactive bands were visualized using the enhanced chemiluminescence detection system (ECL; Amersham, Piscataway, NJ) as previously described (35).

\section{Immunohistochemistry for (P)RR and Wilms' Tumor 1}

To determine the identity of (P)RR-expressing cells in the developing kidney, lung, heart, and brain, we mapped the cellular expression of $(\mathrm{P}) \mathrm{RR}$ protein during mouse organogenesis by immunohistochemistry. Immunolocalization of $(\mathrm{P}) \mathrm{RR}$ protein was performed in CD1 mouse embryos from E14.5 to E18.5 ( $n=3$ per age group). Immunostaining was performed by the immunoperoxidase technique using the Vectastain Elite kit (Vector Laboratories, Burlingame, CA) and a polyclonal goat (P)RR antibody (1:200, AB5959; Abcam). Specificity of immunostaining was documented by the elimination of immunoreactivity after omission of the primary antibody.

\section{Regulation of (P)RR by Ang II in the Developing Kidney}

To determine whether endogenous Ang II regulates (P)RR in the developing kidney, we examined the effect of specific Ang II AT $\mathrm{R}$ and $\mathrm{AT}_{2} \mathrm{R}$ antagonists on (P)RR mRNA expression in newborn metanephroi grown ex vivo. P1 CD1 mouse kidneys were grown on air-fluid interface on polycarbonate transwell filters $(0.5 \mu \mathrm{m}$; Corning Costar, Lowell, MA) inserted into sixwell plates containing Dulbecco's modified Eagle's medium/ F12 medium (Gibco BRL, Carlsbad, CA) alone $(n=3)$ or in the presence of the $\mathrm{AT}_{1} \mathrm{R}$ antagonist candesartan $\left(10^{-6} \mathrm{~mol} / \mathrm{l}\right.$; Sigma, St Louis, MO) $(n=3)$ or $\mathrm{AT}_{2} \mathrm{R}$ antagonist PD123319 $\left(10^{-6} \mathrm{~mol} / \mathrm{l}\right.$; Sigma $)(n=3)$ for $16 \mathrm{~h}$ at $37^{\circ} \mathrm{C}$ and $5 \% \mathrm{CO}_{2}$, and then processed for RNA extraction. Kidney (P)RR mRNA levels were examined by quantitative RT-PCR.

\section{Effect of Animal Sex on (P)RR Gene Expression}

To determine whether there is any difference in the $(P) R R$ gene expression between males and females during postnatal development, we compared $(\mathrm{P}) \mathrm{RR}$ protein expression in male and female brain, kidney, lung, and heart on P10 ( $n=3$ animals per group). 


\section{Statistical Analysis}

Data are presented as mean \pm SD. Differences among the age groups in mRNA and protein levels were analyzed by one-way ANOVA followed by the Bonferroni test. A $P$ value of $<0.05$ was considered statistically significant.

\section{STATEMENT OF FINANCIAL SUPPORT}

This work was supported by National Institutes of Health (Bethesda, MD) grants P20 RR17659 and DK-71699 (to I.V.Y.).

\section{REFERENCES}

1. Navar LG. The kidney in blood pressure regulation and development of hypertension. Med Clin North Am 1997;81:1165-98.

2. Hackenthal E, Paul M, Ganten D, Taugner R. Morphology, physiology, and molecular biology of renin secretion. Physiol Rev 1990;70:1067-116.

3. Schweda F, Kurtz A. Regulation of renin release by local and systemic factors. Rev Physiol Biochem Pharmacol 2011;161:1-44.

4. Cousin C, Bracquart D, Contrepas A, Corvol P, Muller L, Nguyen G. Soluble form of the (pro)renin receptor generated by intracellular cleavage by furin is secreted in plasma. Hypertension 2009;53:1077-82.

5. Nguyen G, Delarue F, Burcklé C, Bouzhir L, Giller T, Sraer JD. Pivotal role of the renin/prorenin receptor in angiotensin II production and cellular responses to renin. J Clin Invest 2002;109:1417-27.

6. Nguyen G, Muller DN. The biology of the (pro)renin receptor. J Am Soc Nephrol 2010;21:18-23.

7. Contrepas A, Walker J, Koulakoff A, et al. A role of the (pro)renin receptor in neuronal cell differentiation. Am J Physiol Regul Integr Comp Physiol 2009;297:R250-7.

8. Advani A, Kelly DJ, Cox AJ, et al. The (Pro)renin receptor: site-specific and functional linkage to the vacuolar H+-ATPase in the kidney. Hypertension 2009;54:261-9.

9. Connelly KA, Advani A, Kim S, et al. The cardiac (pro)renin receptor is primarily expressed in myocyte transverse tubules and is increased in experimental diabetic cardiomyopathy. J Hypertens 2011;29:1175-84.

10. Kinouchi K, Ichihara A, Sano M, et al. The (pro)renin receptor/ATP6AP2 is essential for vacuolar H+-ATPase assembly in murine cardiomyocytes. Circ Res 2010;107:30-4.

11. Oshima Y, Kinouchi K, Ichihara A, et al. Prorenin receptor is essential for normal podocyte structure and function. J Am Soc Nephrol 2011;22:220312.

12. Riediger F, Quack I, Qadri F, et al. Prorenin receptor is essential for podocyte autophagy and survival. J Am Soc Nephrol 2011;22:2193-202.

13. Amsterdam A, Nissen RM, Sun Z, Swindell EC, Farrington S, Hopkins N. Identification of 315 genes essential for early zebrafish development. Proc Natl Acad Sci USA 2004;101:12792-7.

14. Ramser J, Abidi FE, Burckle CA, et al. A unique exonic splice enhancer mutation in a family with X-linked mental retardation and epilepsy points to a novel role of the renin receptor. Hum Mol Genet 2005;14:1019-27.

15. Jones CA, Sigmund CD, McGowan RA, Kane-Haas CM, Gross KW. Expression of murine renin genes during fetal development. Mol Endocrinol 1990;4:375-83.

16. Gomez RA, Lynch KR, Sturgill BC, et al. Distribution of renin mRNA and its protein in the developing kidney. Am J Physiol 1989;257(5 Pt 2):F850-8.

17. Schütz S, Le Moullec JM, Corvol P, Gasc JM. Early expression of all the components of the renin-angiotensin-system in human development. Am J Pathol 1996;149:2067-79.
18. Yosipiv IV, Dipp S, el-Dahr SS. Ontogeny of somatic angiotensin-converting enzyme. Hypertension 1994;23:369-74.

19. Yosipiv IV, el-Dahr SS. Activation of angiotensin-generating systems in the developing rat kidney. Hypertension 1996;27:281-6.

20. Takahashi N, Lopez ML, Cowhig JE Jr, et al. Ren1c homozygous null mice are hypotensive and polyuric, but heterozygotes are indistinguishable from wild-type. J Am Soc Nephrol 2005;16:125-32.

21. Nagata M, Tanimoto K, Fukamizu A, et al. Nephrogenesis and renovascular development in angiotensinogen-deficient mice. Lab Invest 1996;75:74553.

22. Huang Y, Wongamorntham S, Kasting J, et al. Renin increases mesangial cell transforming growth factor-betal and matrix proteins through receptor-mediated, angiotensin II-independent mechanisms. Kidney Int 2006;69:105-13.

23. Schefe JH, Menk M, Reinemund J, et al. A novel signal transduction cascade involving direct physical interaction of the renin/prorenin receptor with the transcription factor promyelocytic zinc finger protein. Circ Res 2006;99:1355-66.

24. Bridgewater D, Cox B, Cain J, et al. Canonical WNT/beta-catenin signaling is required for ureteric branching. Dev Biol 2008;317:83-94.

25. Cruciat CM, Ohkawara B, Acebron SP, et al. Requirement of prorenin receptor and vacuolar $\mathrm{H}+$-ATPase-mediated acidification for Wnt signaling. Science 2010;327:459-63.

26. Buechling T, Bartscherer K, Ohkawara B, et al. Wnt/Frizzled signaling requires $\mathrm{dPRR}$, the Drosophila homolog of the prorenin receptor. Curr Biol 2010;20:1263-8.

27. Fisher CE, Michael L, Barnett MW, Davies JA. Erk MAP kinase regulates branching morphogenesis in the developing mouse kidney. Development 2001;128:4329-38.

28. Tang MJ, Cai Y, Tsai SJ, Wang YK, Dressler GR. Ureteric bud outgrowth in response to RET activation is mediated by phosphatidylinositol 3-kinase. Dev Biol 2002;243:128-36.

29. Burcklé CA, Jan Danser AH, Müller DN, et al. Elevated blood pressure and heart rate in human renin receptor transgenic rats. Hypertension 2006; $47: 552-6$.

30. Hirose T, Hashimoto M, Totsune K, et al. Association of (pro)renin receptor gene polymorphism with blood pressure in Japanese men: the Ohasama study. Am J Hypertens 2009;22:294-9.

31. Hirose T, Hashimoto M, Totsune $\mathrm{K}$, et al. Association of (pro)renin receptor gene polymorphisms with lacunar infarction and left ventricular hypertrophy in Japanese women: the Ohasama study. Hypertens Res 2011;34:530-5.

32. Shan Z, Shi P, Cuadra AE, et al. Involvement of the brain (pro)renin receptor in cardiovascular homeostasis. Circ Res 2010;107:934-8.

33. Anderson C, Catoe H, Werner R. MIR-206 regulates connexin 43 expression during skeletal muscle development. Nucleic Acids Res 2006;34:586371.

34. Wang Y, Pringle KG, Sykes SD, et al. Fetal sex affects expression of reninangiotensin system components in term human decidua. Endocrinology 2012;153:462-8.

35. Yosypiv IV, Boh MK, Spera MA, El-Dahr SS. Downregulation of Spry-1, an inhibitor of GDNF/Ret, causes angiotensin II-induced ureteric bud branching. Kidney Int 2008;74:1287-93.

36. Yperman J, De Visscher G, Holvoet P, Flameng W. Beta-actin cannot be used as a control for gene expression in ovine interstitial cells derived from heart valves. J Heart Valve Dis 2004;13:848-53. 